\title{
Patch Testing for Contact Allergy and Allergic Contact Dermatitis ${ }^{\S}$
}

\author{
Radoslaw Spiewak*
}

\begin{abstract}
Institute of Public Health, Jagiellonian University Medical College, Krakow, Poland; and Institute of Dermatology, Krakow, Poland
\end{abstract}

\begin{abstract}
Contact allergy (CA) is alteration of immune response with readiness to develop an inflammatory reaction against a specific substance of low molecular weight (hapten). The prevalence of CA is estimated at 26-40\% among adults, and $21-36 \%$ children. A proportion of people with CA will remain asymptomatic, among the rest, the most frequent clinical manifestation is allergic contact dermatitis (ACD) with lifetime prevalence estimated at $10 \%$. Less frequent manifestations include allergic contact stomatitis, conjunctivitis, vaginitis, systemic reactions, implant intolerance, and rarely urticaria, asthma, and allergic rhinitis. Patch test (epicutaneous test) is the gold standard in the diagnosis of CA and ACD: Performing the test significantly increases probability of accurate diagnosis, reduces costs of treatment, and leads to improved patients' quality of life. Patch test results may be influenced by patient's medication and health status, and interpretation requires due knowledge and experience. Other diagnostic methods are more laborious and not validated; no in vitro tests are available for routine application at present.
\end{abstract}

Keywords: Contact allergy, allergic contact dermatitis, diagnosis, patch tests, use tests, intradermal tests, oral provocation.

${ }^{\S}$ Dedicated to Professor Brunello Wüthrich (Zürich) - a Great Allergist, on his 70th Birthday

Contact allergy (CA, synonym: contact hypersensitivity, CHS) is the body's readiness to develop an inflammatory reaction against a specific substance of low molecular weight (hapten) at skin contact. This state of hypersensitivity is acquired during previous exposures to the hapten. In typical situations, numerous exposures are necessary to induce CA $[1,2]$, depending on the sensitizing potency of the hapten $[3$, 4]. The term "contact allergy" refers to a state of altered response of the immune system to a specific substance, which is not synonymous with disease: Certain proportion of people with CA will never develop clinical symptoms. Among those symptomatic, vast majority will develop allergic contact dermatitis (ACD, synonym: allergic contact eczema). Other diseases caused by contact allergy include allergic contact stomatitis [5], allergic contact conjunctivitis [6], allergic vaginitis [7], or systemic reactions [8]. CA is also incriminated as a possible cause of rejected orthopedic implants [9], dental implants [10], pacemakers [11] and stents [12]. Furthermore, CA was proposed as explanation for some cases of urticaria [13], asthma [14], and allergic rhinitis [15]. In daily usage, the terms "contact allergy" and "allergic contact dermatitis" are too frequently used as synonyms, which in the light of the above facts seems unjustified. The relationship between the terms "contact allergy" and "allergic contact dermatitis" is analogous to that between "atopic allergy" and "allergic rhinitis" or "allergic asthma".

\section{EPIDEMIOLOGY OF CONTACT ALLERGY}

The prevalence of CA in the general population is estimated at $26-40 \%$ in adults $[16,17]$ and $21-36 \%$ children [18].

\footnotetext{
*Address correspondence to this author at the Institute of Public Health, Jagiellonian University Medical College, ul. Lentza 6 M 17, 31-312 Krakow, Poland; Tel: + 481263600 51; Fax: + 481241662 62;

E-mail: spiewak@onet.eu
}

In Europe and most of the world, most frequent contact sensitizers are nickel, thiomersal (Merthiolate) and fragrances. Sensitization to nickel is found in $13-17 \%$ adults $[16,19]$, approx. $10 \%$ adolescents $[20]$ and $7-9 \%$ children $[18,21]$. Altogether, the number of nickel-allergic people in the EU (including Bulgaria and Romania) could be estimated at 65 million, including 51 million women and 14 million men [22]. Although not all people with CA to nickel will develop symptoms of disease, the majority of them eventually will. Women are at much higher risk of acquiring allergy to nickel (20.4\% versus $5.8 \%$ in men) [16]. Differences in both physiology and exposure were postulated to explain this disparity [23]. It seems, however, that the soundest explanation is the difference in exposure, especially early beginning of wearing earrings in girls. In Denmark, legal restrictions on earrings with high nickel content resulted in a $64 \%$-decrease of the risk for nickel allergy among girls wearing earrings [24]. Encouraged by this experience and considering nickel allergy as serious burden to public health, European Parliament and European Council imposed restrictions on the marketing and use in the EU of object coming into close and prolonged contact with the skin that release large amounts of nickel (so-called "Nickel Directive"), that came fully into force in July 2001 [25].

According to frequency of positive skin reaction on patch testing, the next rank is occupied by thiomersal (syn. Thimerosal, Thimerosol, Merthiolate). Thiomersal is used as preservative in vaccines, cosmetics and other easily spoiling products. CA to thiomersal was found in 5\% adult Germans [16]. In Poland, positive patch test with this preservative was found in $8 \%$ children [21] and $18.5 \%$ young adults [20]. A possible explanation of this difference is that between the 13 th and 18th year of life, repeated obligatory prophylactic vaccinations with thiomersal-preserved vaccines are carried out. This can possibly lead to alterations in the immune re- 
sponse. Interestingly, despite the high prevalence of contact sensitization to thiomersal and the scale of obligatory vaccination with thiomersal-containing vaccines, only a few cases of ACD caused by this preservative were reported worldwide. In 2 prospective studies, none of persons with CA to thiomersal has experienced adverse symptoms after vaccination with thiomersal-containing vaccines $[26,27]$. ACD was observed only if the vaccine was administered subcutaneously (instead of the recommended intramuscular route), which underlines the importance of the skin route in the induction and elicitation of ACD. The above observations also turn attention on the question of the clinical relevance of a positive patch test result, which will be discussed later in this article.

In the above-mentioned German study of adult general population, patch tests with fragrances were positive more frequently $(15.9 \%)$ than with nickel [16]. However, the test substance "fragrance mix" is not a single hapten, but mixture of 8 most frequently sensitizing fragrance compounds (Cinnamic alcohol, Cinnamic aldehyde, Hydroxycitronellal, Amylcinnamaldehyde, Geraniol, Eugenol, Isoeugenol, Oak moss absolute), and the emulsifier Sorbitan sesquioleate, each of these being a less frequent sensitizer than nickel. These and other frequent sensitizers are included into standard series that are shown in Table $\mathbf{1}$.

\section{DETECTING CONTACT ALLERGY}

In the detection of $\mathrm{CA}$, and in the diagnosis of allergic contact dermatitis (ACD), patch test is the generally-accepted method of choice and the "gold standard" [28-31]. In principle, patch test relies on provoking skin inflammation (dermatitis) on a very limited skin area (less than $1 \mathrm{~cm}^{2}$ ) under controlled conditions. Development of inflammatory reaction at the site of application of a particular substance is considered as a proof of hypersensitivity, and may also be viewed as reproduction of the disease (Fig. 1). Thus, patch test is both a screening test and a provocation test in the target organ skin. The benefits of patch testing in patients with suspicion of ACD include reduction of the treatment cost, and increased patients' quality of life. The percentage of final diagnoses is higher among patients who had undergone patch testing $(88 \%$ as compared to $69 \%$ among those non-tested). Most notably, patch tests shorten more than 20 times the time lapse from the first visit to final diagnosis (in average, from 175 days down to 8). Patch testing helps in identification and avoidance of offending haptens, thus helping in limiting symptoms of the disease. As a result, reduction of symptoms by at least $75 \%$ was observed in $66 \%$ patch-tested patients, as compared to $51 \%$ in those not tested [32].

\section{INDICATIONS AND CONTRAINDICATIONS FOR PATCH TESTING}

Patch tests should be performed in every case of chronic and/or recurrent itchy dermatitis (eczema) or lichenification, whenever a possibility exists that CA may be the cause or a complication of the disease [33]. Thus, beside the suspicion of allergic contact dermatitis, patch tests are also indicated in a variety of inflammatory skin diseases including those regarded as "endogenous": atopic eczema, seborrheic dermatitis, stasis dermatitis, eczema around leg ulcers, irritant contact dermatitis, etc. This is due to the fact that CA, and subsequent $\mathrm{ACD}$ can develop as a secondary phenomenon in the course of other dermatoses - e.g. sensitization to topical therapeutics used on long-term basis in eczema or psoriasis $[34,35]$. The emerging secondary ACD may complicate the course of (or even replace) the primary disease [36, 37]. Contraindications for patch testing include immune deficiencies, immunosuppressive treatment (drugs, sunbathing, sunbeds), and autoimmune diseases. Pregnancy and lactation are conditional contraindications, as there are no data on the safety of the test for the mother and child [38].

\section{APPLICATION OF PATCH TESTS}

In a typical patch test protocol, certain amounts of suspected haptens are applied onto the skin for $48 \mathrm{~h}(24 \mathrm{~h}$ in some countries), and the subsequent assessment of skin reaction is done at defined time points, typically after 2, 3 and 4 days [31]. Additional reading after 7 days may reveal up to $10 \%$ positive reactions that were negative on previous checks. Examples of haptens, for which allergic skin reaction may develop later than after 4 days are: neomycin, tixocortol pivalate, and nickel $[39,40]$. The test substances are applied onto the skin with the use of specially devised chambers on sticking plaster. If possible, tests should be mounted on the patient's back. Upper dorsum is the most convenient localization both for doctor and patient, and most of patch test validation was carried out in this area. Therefore, applying tests in other body areas (e.g. arms, forearms, thighs, abdomen) should be restricted to exceptional situations and should be performed by an experienced doctor due to difficulties of interpretation.

The most widely used patch test application systems worldwide are: traditional round aluminium Finn Chambers (Epitest), squaric IQ Ultra Chambers made of soft polyethylene foam (Chemotechnique Diagnostics), and TRUE Test (Thin-layer Rapid Use Epicutaneous Test, Mekos). Finn Chambers have to be filled with test substances immediately before application, while IQ Chambers may be filled immediately before testing or in advance and then stored in refrigerator for a few days. TRUE Test is loaded with haptens already during production. Material, of which the chambers are made may influence the reliability of patch tests: Finn Chambers are made of aluminium, which may come into (or catalyze) chemical reactions with test substance (e.g. with thimerosal); there is also a risk of false positive reactions in people allergic to aluminium $[41,42]$. The manufacturer answered to this problem with introduction of a special series of test chambers, in which aluminium is covered by a layer of polypropylene. IQ Ultra Chambers are made of chemically inert polyethylene, which does not react with the haptens and does not sensitize patients. The shape of the test chamber may also influence the final reading: IQ Ultra Chambers and TRUE Test are squaric, which allows a better discrimination between allergic and irritant reactions. In allergic reaction, inflammatory infiltrate typically expands beyond the borders of the contact area, which can be seen as "rounding" of the testing areas' corners. In contrast, irritant reaction is typically restricted to the area of contact, so that the shape of the inflamed area remains sharp.

\section{VEHICLES FOR TEST SUBSTANCES}

White petrolatum (pet.) and water (aq.) are most frequently used vehicles (solvents) for patch test substances. In some cases, haptens are also dissolved in olive oil, rape oil, 
acetone, alcohol etc. Typically, $20 \mu \mathrm{l}$ of petrolatum-based test substances or $30 \mu \mathrm{l}$ of liquid preparations are loaded into chambers. The accuracy of the volume is one of the factors that determine the test's reproducibility [43]. TRUE patches are filled with test substances already during production phase, which ensures the accuracy of hapten dosage. Overall, the sensitivity of patch test is influenced by the choice of application system: Comparative studies have demonstrated that patch test applied with IQ Chamber is more sensitive than TRUE Test [44], while TRUE Test is slightly more sensitive than patch tests with the traditional Finn Chambers [45].

\section{SELECTING HAPTENS FOR PATCH TESTING}

Test substances should be chosen accordingly to clinical history, and include haptens suspected of provoking the disease. As not in every case the patient's history allows for identification of the offending hapten, epidemiological situation in a given geographical area or in a given risk group should also be taken into account. This means that "standard series" of haptens should be applied in every patient along with suspect substances indicated by clinical picture and history [31]. "Standard series" are collections of substances that are the most frequent sensitizers in the population of a given geographical area (e.g. country or continent) or groups of specific exposure (e.g. occupational, lifestyle, certain risk factors). Standard series are periodically updated, accordingly to recent epidemiological trends. In the past, "national" standard series were used in most countries. It does not seem reasonable anymore nowadays, in the era of globalized trade of goods, which frequently are sources of sensitizing haptens. As some intercontinental differences still are preserved, implementation of "continental series" seems most reasonable for the time being.

The most important criterion for including a hapten into a standard series is the prevalence of sensitization in the target group, which also means a chance for obtaining a positive result in a tested person. Inspired from the Pareto rule (socalled ' $20-80$ ' rule), it is postulated that an "ideal standard series" should be capable of identifying offending haptens in at least $80 \%$ of ACD patients from a given population [46, 47]. It is difficult to assess whether this goal has been reached yet. In 1992, a multicenter study demonstrated that the contemporary European Standard Series (24 test substances at that time) explained only $31-41 \%$ of all tested cases [46]. Since that time, the series was revised several times (compare the annotations in the caption for Table 1). After last revision in March 2008, the series consists of 28 test substances (single haptens or hapten mixtures), and has a new name "European Baseline Series" (EBS), instead of "European Standard Series" (possibly to avoid confusion of the name with industrial standards). EBS is recommended by the European Society of Contact Dermatitis (ESCD) and European Environmental Contact Dermatitis Research Group (EECDRG) as the first choice for testing patients with the suspicion of contact allergy [48]. Current listing of the EBS demonstrates that fragrances are gaining on relevance as contact sensitizers. Recent additions to the series are Fragrance mix II (Citronellal, Citral, Coumarin, Lyral, Farnesol and alpha-Hexylcinnamic aldehyde) and a separate ingredient of the mix - Lyral. Addition of these substances is expected to improve the detection rates $5 \%$ and $1.5-3 \%$, respectively. In Table 1, a comparison of European Baseline Series, North American Series (NAS), the International Standard Series (ISS), and TRUE Test is given. Although the latter one is not a standard series, it is cited here as an "instant" patch test product, which is quite popular among doctors who keep their contact allergy diagnostics at basic level. TRUE test is a closed system, with pre-selected 29 substances only (24 in some countries), which means that the doctor cannot adjust the selection of test substances accordingly to clinical picture and patient's history.

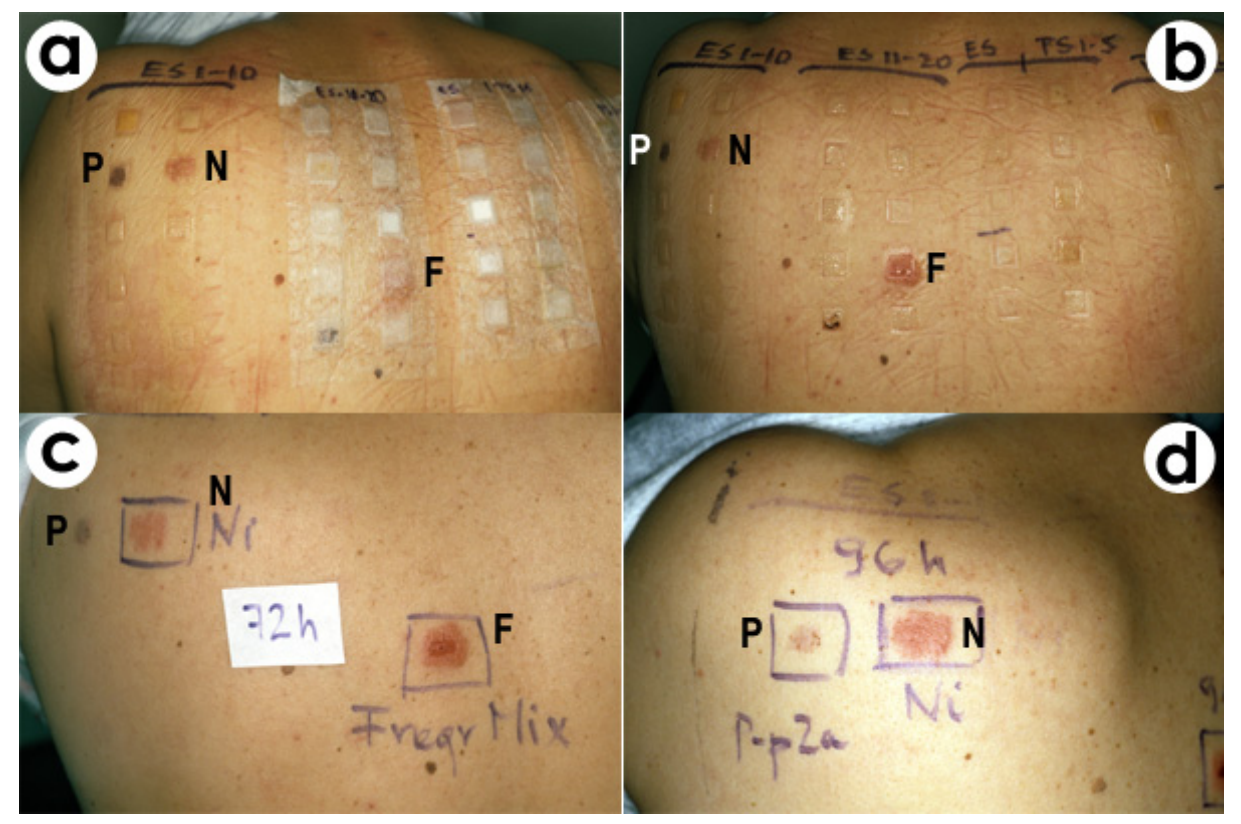

Fig. (1). Patch test during (a) and immediately after (b) removal of the test plasters, 2 days after application. Visible is positive (++) reaction to nickel $(\mathrm{N})$ and extremely positive $(+++)$ reaction to Fragrance Mix $(\mathrm{F})$. On Day $3(\mathbf{c})$, a questionable reaction $(?+)$ appears on the site of pphenylenediamine $(\mathrm{P})$. After 4 days $(\mathbf{d})$, further development of test reaction to nickel $(+++)$, and p-phenylenediamine $(+)$. 
Table 1. Contents of the Most Widely Used Patch Test Series

\begin{tabular}{|c|c|c|c|c|}
\hline Test Substance & NAS & EBS & ISS & TRUE \\
\hline Amerchol L 101 & - & & & \\
\hline Bacitracin & $\bullet$ & & & \\
\hline Balsam Peru & $\bullet$ & $\bullet$ & $\bullet$ & $\bullet$ \\
\hline Benzocaine & $\bullet$ & $\bullet$ & & \\
\hline Black rubber mix & & $\mathrm{a}$ & & $\bullet$ \\
\hline Budesonide & $\bullet$ & $\bullet$ & $\bullet$ & $\bullet$ \\
\hline 4-tert-Butylphenolformaldehyde resin & $\bullet$ & $\bullet$ & $\bullet$ & $\bullet$ \\
\hline 2-Bromo-2-nitropropane-1,3-diol & $\bullet$ & & & \\
\hline Caine mix & & & & $\bullet$ \\
\hline Carba mix & $\bullet$ & $\mathrm{b}$ & & $\bullet$ \\
\hline 1-(3-Chloroallyl)-3,5,7-triaza-1-azoniaadamantane chloride (Quaternium 15) & $\bullet$ & $\bullet$ & $\bullet$ & $\bullet$ \\
\hline 5-Chloro-2-methyl-4-isothiazolin-3-one (Kathon CG) & $\bullet$ & $\bullet$ & $\bullet$ & $\bullet$ \\
\hline 4-Chloro-3,5-xylenol & $\bullet$ & & & \\
\hline Cinnamic aldehyde & $\bullet$ & & & \\
\hline Clioquinol & & $\bullet$ & & \\
\hline Cobalt (II) chloride & $\bullet$ & $\bullet$ & & $\bullet$ \\
\hline Cocamidopropylbetaine & $\bullet$ & & & \\
\hline Colophony & $\bullet$ & $\bullet$ & $\bullet$ & $\bullet$ \\
\hline Compositae mix & $\bullet$ & & & \\
\hline Dimethyloldihydroxyethyleneurea (Fix CPN) & $\bullet$ & & & \\
\hline 2,5-Diazolidinylurea & $\bullet$ & & & $\bullet$ \\
\hline Disperse Blue mix 106/124 & $\bullet$ & & & \\
\hline DMDM Hydantoin & $\bullet$ & & & \\
\hline Epoxy resin & $\bullet$ & $\bullet$ & $\bullet$ & $\bullet$ \\
\hline Ethyl acrylate & $\bullet$ & & & \\
\hline Ethylenediamine dihydrochloride & $\bullet$ & $\mathrm{c}$ & & $\bullet$ \\
\hline Ethyleneurea, melamine formaldehyde mix & $\bullet$ & & & \\
\hline Formaldehyde & $\bullet$ & $\bullet$ & $\bullet$ & $\bullet$ \\
\hline Fragrance mix & $\bullet$ & $\bullet$ & $\bullet$ & $\bullet$ \\
\hline Fragrance mix II & $\bullet$ & $\bullet$ & & \\
\hline Glyceryl monothioglycolate 1.0 & $\bullet$ & & & \\
\hline Glutaraldehyde & $\bullet$ & & & \\
\hline Hydrocortisone-17-butyrate & $\bullet$ & & & \\
\hline 2-Hydroxy-4-methoxybenzophenone & $\bullet$ & & & \\
\hline Imidazolidinyl urea & $\bullet$ & & $\bullet$ & $\bullet$ \\
\hline Iodopropynyl butyl carbamate & $\bullet$ & & & \\
\hline N-Isopropyl-N-phenyl-4-phenylenediamine (IPPD) & $\bullet$ & $\bullet$ & & \\
\hline Lyral & & $\bullet$ & & \\
\hline Mercapto mix & $\bullet$ & $\bullet$ & $\bullet$ & $\bullet$ \\
\hline 2-Mercaptobenzothiazole & $\bullet$ & $\bullet$ & $\bullet$ & $\bullet$ \\
\hline 2-Methoxy-6-n-pentyl-4-benzoquinone (Primin) & & $\bullet$ & & \\
\hline Methyldibromoglutaronitrile (1,2-Dibromo-2,4-dicyanobutane) & $\bullet$ & $\bullet$ & $\bullet$ & \\
\hline Methyl methacrylate & $\bullet$ & & & \\
\hline Mixed dialkyl thiourea & $\bullet$ & & & \\
\hline Neomycin sulfate & $\bullet$ & $\bullet$ & $\bullet$ & $\bullet$ \\
\hline Nickel sulfate & $\bullet$ & $\bullet$ & $\bullet$ & $\bullet$ \\
\hline Paraben mix & $\bullet$ & $\bullet$ & & $\bullet$ \\
\hline 4-Phenylenediamine base & $\bullet$ & $\bullet$ & $\bullet$ & $\bullet$ \\
\hline Potassium dichromate & $\bullet$ & $\bullet$ & $\bullet$ & $\bullet$ \\
\hline Propylene glycol & $\bullet$ & & & \\
\hline Quinoline mix & & $\mathrm{d}$ & & $\bullet$ \\
\hline Sesquiterpenelactone mix & $\bullet$ & $\bullet$ & & \\
\hline Thiomersal & & & & $\bullet$ \\
\hline Thiuram mix & $\bullet$ & $\bullet$ & $\bullet$ & $\bullet$ \\
\hline Tixocortol-21-pivalate & $\bullet$ & $\bullet$ & $\bullet$ & $\bullet$ \\
\hline Toluene sulfonamide formaldehyde resin & $\bullet$ & & & \\
\hline Triamcinolone acetonide & $\bullet$ & & & \\
\hline Wool alcohols & & $\bullet$ & $\bullet$ & $\bullet$ \\
\hline
\end{tabular}

NAS - North American Series; EBS - European Baseline Series; ISS - International Standard Series; TRUE - Thin-layer Rapid Use Epicutaneous Tests. (a) Black rubber mix was replaced in 1995 with the major sensitizing component of the mix IPPD [49]; (b) Carba mix was withdrawn in 1988 [50]; (c) Ethylenediamine dihydrochloride was withdrawn in 1995 [49]; (d) Quinoline mix was replaced in 1995 with Clioquinol - the major sensitizing component of the mix [49]. 


\section{INTERPRETATION OF PATCH TEST RESULTS}

When a person is sensitized to a test substance, an inflammatory reaction will develop in the exposed area. The intensity of the reaction is scored and recorded according to the rules of the International Contact Dermatitis Research Group (ICDRG), presented in Table 2 and Fig. (2). The reading and interpretation of patch results requires training and some experience. In doubtful cases, verification of the tests in a reference center may be necessary [51]. Crucial is doctor's ability to differentiate between specific allergic reactions and irritant ones, which is not always an easy task. For example, about 5\% of persons tested with $1 \%$ cobalt chloride will develop local microscopic bleeding from capillary vessels (petechiae) due to the hapten's irritant properties. Inexperienced investigator might mistakenly interpret such reddish efflorescences as erythema, leading to a false conclusion of CA to cobalt. Similar changes can also be provoked by p-phenylenediamine (PPD), N-Isopropyl-N-phenyl-p-phenylenediamine (IPPD) and certain drugs [31]. In case of patch test with corticosteroids, it must be kept in mind that beside their possible allergizing potential, these substances strongly inhibit inflammatory reaction. Therefore, in case of CA to corticosteroids, positive reactions may be considerably weaker, develop with delay, and take annular shape (lower concentration, thus lower antiinflammatory effect at edges of the test area). The above are only a few examples to illustrate that interpretation of patch tests requires a good understanding of skin efflorescences, pathophysiology of the skin, as well as knowledge of pharmacological, kinetic and toxicological properties of substances tested. Therefore, reading and interpretation of patch test should be carried out by a well-trained and experienced dermatologist or allergist [52].

\section{DIAGNOSIS OF PHOTOALLERGIC CONTACT DERMATITIS (PACD)}

In PACD, the additional factor required for the development of skin symptoms is the light, typically this is ultraviolet (UV) light. Under photoactivation, precursors are converted into offending haptens, or energy carried by the photons is necessary for initiation of binding between hapten and carrier protein. Diagnosis of photoallergic contact dermatitis requires respective modification of patch tests, i.e. irradiation of tested skin area with UV. Typically, UVA (wavelength 320-400 nm) is used; in rare cases UVB (290-320 nm) is necessary for the initiation of allergic reaction. The UVA dose used at photopatch testing is $5-10 \mathrm{~J} / \mathrm{cm}^{2}$ or, alternatively, $1 / 2$ of Minimal Erythema Dose (MED) determined individually for the tested person [53]. The haptens tested are applied in double sets, with only one being irradiated. While interpreting photopatch test results, both sets of haptens are compared: the "bright" side (patch tests irradiated with UV) with "dark" side (not exposed to UV). A positive result on the "bright" side with a negative result on the "dark" side suggests photoallergy, equal responses on both sides - "classical" contact allergy.

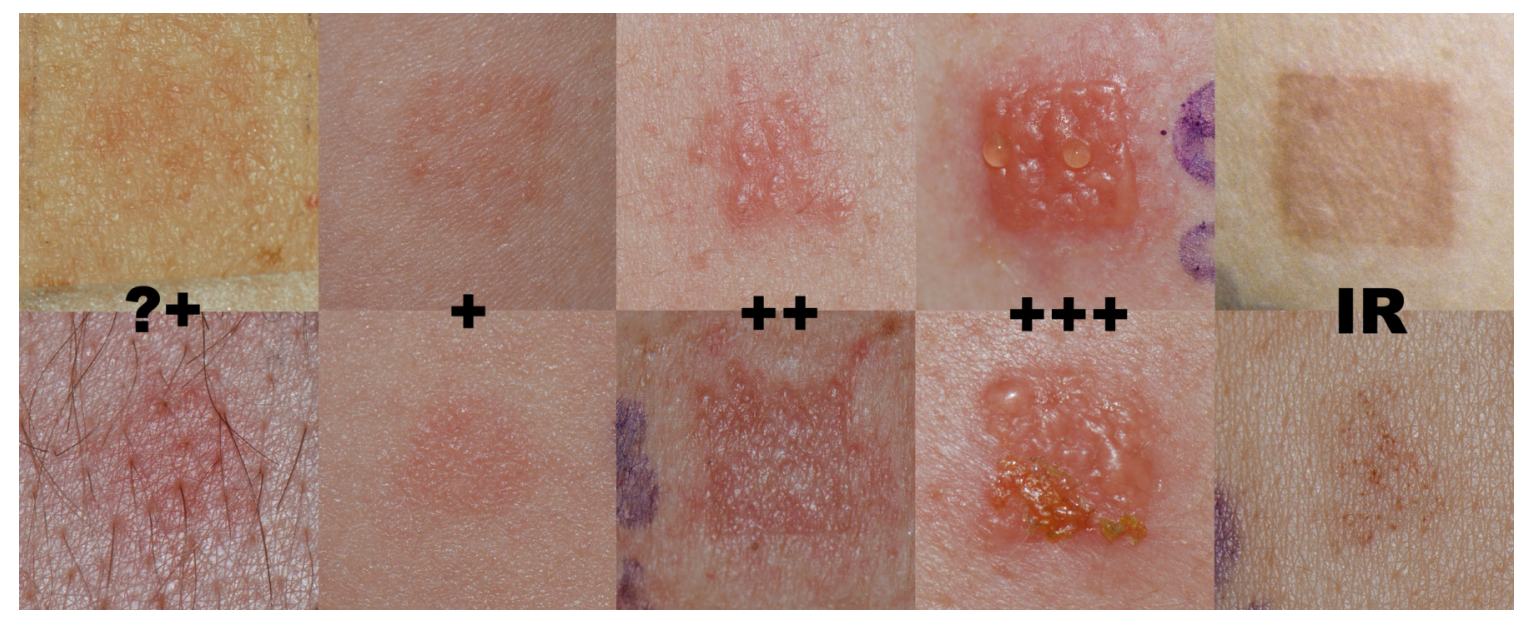

Fig. (2). Notation of positive patch test results according to ICDRG. Compare description in Table 2.

Table 2. Notation of Patch Test Results

\begin{tabular}{|c|l|l|}
\hline Notation & \multicolumn{1}{|c|}{ Description } & Interpretation \\
\hline \hline- or $\varnothing$ & no skin changes in the tested area & negative \\
\hline$?+$ & faint, non-palpable erythema & $\begin{array}{l}\text { doubtful reaction; most authors do not consider this } \\
\text { kind of reaction as a proof of sensitization }\end{array}$ \\
\hline+ & $\begin{array}{l}\text { palpable erythema - moderate edema or infiltrate, papules not present or scarce, } \\
\text { vesicles not present }\end{array}$ & weak reaction \\
\hline++ & strong infiltrate, numerous papules, vesicles present & strong reaction \\
\hline+++ & coalescing vesicles, bullae or ulceration & extreme reaction \\
\hline NT & Not Tested & $\begin{array}{l}\text { inflammation sharply limited to the exposed area, lack of infiltrate, small petechiae, } \\
\text { pustules, and efflorescences other than papules and vesicles. }\end{array}$ \\
\hline IR & & many problems upon interpretation. \\
\hline
\end{tabular}




\section{CLINICAL RELEVANCE OF A POSITIVE PATCH TEST}

As already mentioned, a positive result of a patch test (contact allergy) is not equivalent with the diagnosis of allergic contact dermatitis. Some persons with positive patch test result will never experience any clinical symptoms after exposure to the hapten (compare the above-discussed example of thiomersal). Therefore, the clinical relevance of positive patch test should be considered in each case. This means that the answer to the question "does the positive patch test result really explain the patient's symptoms?" should be sought for in each case. In the assessment of clinical relevance, the COADEX classification may be very helpful (Table 3) $[53,54]$. While interpreting patch test results, it should be also kept in mind that increasing the number of tested substances will lead to an increased risk of false positive or "accidentally positive" reactions (truly positive, yet irrelevant for present symptoms) [55]. application system. The reproducibility of patch test depends on the hapten, and is high for corticosteroids $(66-100 \%)$ and nickel $(80 \%)$, but relatively low $(40 \%)$ for formaldehyde [63, 64]. As other clinical tests, patch tests are compromised by a range of factors, such as inter-observer variability [65], site-tosite variability [66], and test-to-test variability [67]. Patch test results may be furthermore influenced by the time of reading $[39,40]$, quality of test substances used [68], previous ultraviolet irradiation of the skin $[69,70]$, topical and oral steroids [71, 72], phase of menstrual cycle [73]. In some cases, excessive irritation of the skin during patch test makes the reading and interpretation difficult or impossible. This situation, referred to as "angry back" or "excited skin syndrome" should always be considered when 5 or more positive results are seen in one test series $[74,75]$.

\section{ADVERSE EFFECTS OF PATCH TESTS}

Despite the fact that patch tests are relatively safe and have been used for more than a century now, one must not

Table 3. The COADEX System for Assigning Relevance to Positive Patch Test Reactions. After [53, 54], Modified

\begin{tabular}{|c|l|}
\hline Code & Meaning \\
\hline \hline $\mathrm{C}$ (current) & $\begin{array}{l}\text { Current relevance: The patient had been exposed to allergen prior to the current episode of dermatitis, improvement of the } \\
\text { disease after cessation of exposure }\end{array}$ \\
\hline $\mathrm{O}$ (old) & Old or past relevance - Past episodes of dermatitis from exposure to the allergen \\
\hline A (active sensitization) & Actively sensitized - Patient presents with a sensitization (late) reaction \\
\hline $\mathrm{D}$ (doubtful) & Relevance difficult to assess, no traceable relationship between positive test and the disease \\
\hline E (exposed) & History of previous exposures that did not cause dermatitis \\
\hline $\mathrm{X}$ (cross-reaction) & The positive test is due to cross-reaction with another hapten that is really of clinical relevance \\
\hline
\end{tabular}

\section{PATCH TESTING IN CHILDREN}

CA affects $13-37 \%$ of children's general population [18]. The topic of patch testing in children is marked with conflicting views and statements, from rejection of patch testing in the early years $[56,57]$, to suggestions that children can be tested already from early infancy exactly the same way as adults [58, 59]. During such discussions, a hypothetical "immune immaturity" (reduction of specific response) in the child's skin is frequently pointed on, with little scientific evidence available to support this view. In the author's opinion, it may seem somewhat illogical to assume an "immune immaturity" of child's skin for patch testing, while the skin appears "mature enough" for developing allergic skin symptoms that pose indication for patch testing. Nowadays, most authors suggest testing children with the same substances and concentrations as the adults, however, in order to tackle the technical problem of child's dorsum small size, reduced patch tests series for children were also proposed [60]. A recent study also suggested halving concentrations of certain test substances (Nickel sulfate, Formaldehyde, Carba mix, Mercaptobenzothiazole, Mercapto mix, Para-phenylenediamine, Thiuram) in children under 5 years old [61].

\section{LIMITATIONS OF PATCH TESTS}

The specificity and sensitivity of patch tests is typically within the range of $70-80 \%$, depending on the hapten [62]. As already mentioned, the sensitivity partly depends also on the forget about possible adverse effects. These include a recall of active ACD in the previously involved areas, generalization of ACD, the above-mentioned "angry back syndrome", irritation of the skin by adhesive material used for mounting patch tests, and rarely contact urticaria and anaphylaxis. Individual case reports were also published of postinflammatory pigmentation disorders, scarring and development of millia in the sites of positive reactions [38]. Discussed is also the possibility of iatrogenic sensitization during patch testing, which is thought to be characterized by a very late positivization of the patch test results (10 days or more after application). However, there is so far no scientific evidence for that, and from author's experience, in some patients with late positivization, prior existence of CA to the hapten can be confirmed convincingly. Isaksson has also suggested that late appearance of the reaction is not necessarily connected to active sensitization during patch test [76]. Overall, the risk of adverse effect of patch tests is very low, provided that they are done according to expert guidelines, and tests substances are used with confirmed safety profile (e.g. diagnostic substances available commercially) [77].

\section{OTHER CLINICAL TESTS}

The procedures described below are used when patch test results are inconclusive or contradict the clinical picture or patients' history. They should be restricted to specialized centers, as the determination of indications and contraindica- 
tions, and interpretation of the results require specialist knowledge and experience with the tests.

Intradermal test with haptens is considered more sensitive than patch test $[78,79]$. It allows the diagnosis of CA to nickel already after 24 hours [80]. This test is considered especially helpful in the diagnosis of CA to corticosteroids [81]. Nowadays, taking into account strict regulations on the substances used in diagnosis and therapy, these tests are mainly restricted to drugs suitable for injections (antibiotics, steroids, etc.).

"Use tests" are helpful either in final confirmation of contact hypersensitivity to a hapten, or in the assessment of clinical relevance of an equivocal result of patch test (Fig. 3). The idea behind such tests is to mimic everyday exposure to the suspected hapten in a controlled way. Several variants and names were proposed: Provocative Use Test (PUT) [82, 83], Use Test [84], and Repeated Open Application Test (ROAT) $[83,85]$. Despite some differences, in all of these tests a small amount $(0.1 \mathrm{ml})$ of patch test substance (or e.g. a cosmetic) is applied twice daily onto certain area of the skin (ulnar fossa, axilla, arm) during a period of 14-28 days. This mimics everyday exposure to a hapten better than patch test. The procedure is stopped when unequivocal symptoms of dermatitis develop in the exposed site (Fig. 4). Use tests are laborious, time-consuming, and require a disciplined and co-operative patient. The repeated application might possibly increase the risk of iatrogenic induction, or aggravation of sensitization. Therefore, use tests should be restricted to doubtful cases, where confirmation of the sensitization promises real benefits to the patient's health.

Oral provocation test was proposed for the diagnosis of systemic ACD and pompholyx (hand and/or foot dermatitis characterized by the presence of vesicles or bullae - the allergic etiology of this disease has not been proven). Oral provocation tests have been carried out with nickel, gold, chromium, cobalt, balsam Peru, and drugs [86-91]. A careful consideration of the possible risk versus expected benefit is required in each case, as systemic application of hapten may provoke erythroderma - a generalized inflammation of the skin that may require intensive therapy in hospital conditions.

\section{PATCH TEST AND ATOPIC ECZEMA}

For many years, a conviction that atopy and contact allergy would exclude each other was popular among some doctors and has brought much misunderstanding, as reviewed in [20]. A peculiar form of this belief was the stereotype (seemingly most popular among pediatricians) that eczema in children is always atopic (reviewed in [18]). Some additional confusion has been added to this issue, when atopy patch test (see below) was introduced into clinical practice - a term putting together atopy and patch tests that are generally associated with CA. Recent data show convincingly that atopy and CA are independent phenomena and may either appear separately or coincide with each other [20]. CA and ACD are not uncommon in children, also in those with atopic eczema [18]. Contrary to what was suggested in the past, it appears that no modifications in the procedure are necessary when carrying out patch tests in patients with atopic eczema [92].

\section{ATOPY PATCH TEST}

The introduction of the Atopy Patch Test (APT) has brought some confusion into the science of patch testing. The mode of application of APT is similar to "classical"

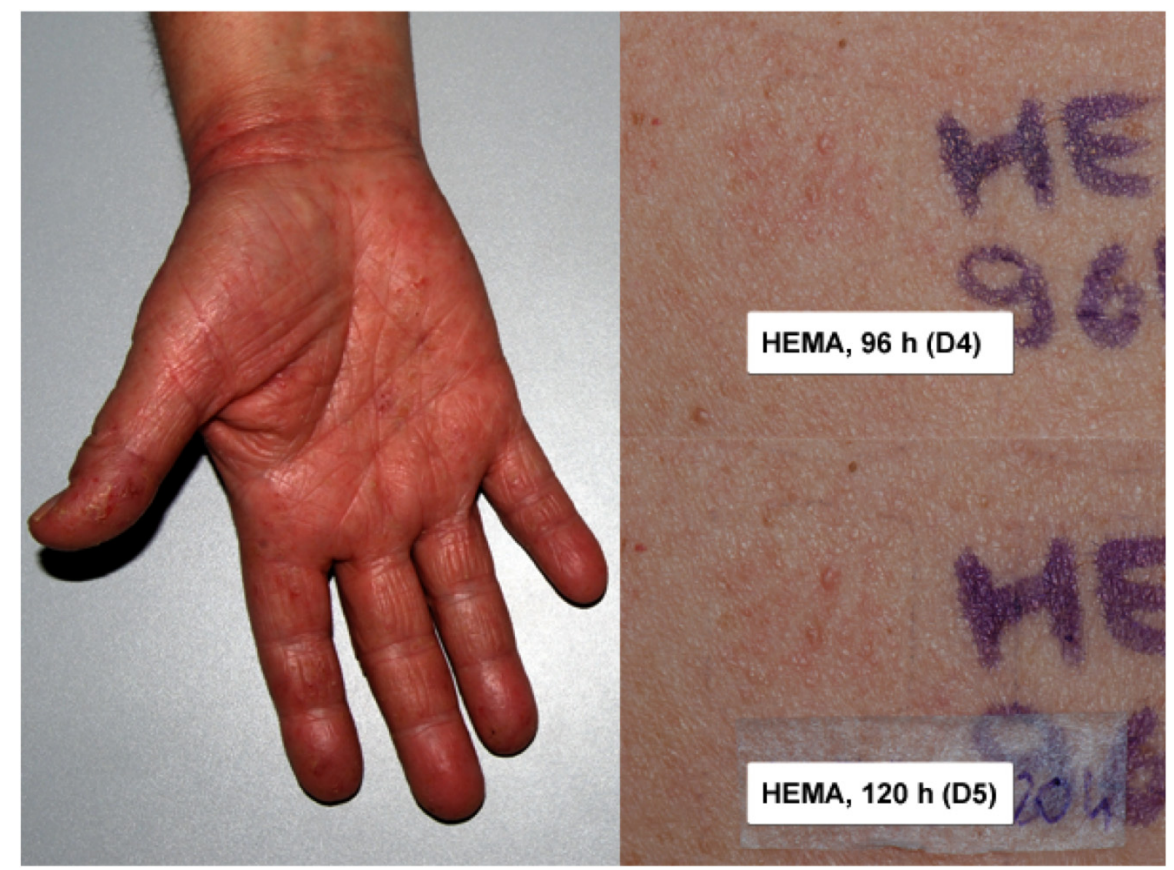

Fig. (3). Hand dermatitis in a dentist with history of improvement during holidays and relapses when at work. Patch test with dental series has demonstrated a strongly positive $(++)$ reaction to mercury (not shown), however, no mercury-containing materials were used by the dentist at that time. After 96 hours, an atypical reaction - single, dispersed papules and vesicles, with slight erythema and no palpable infiltrate - appeared to 2-Hydroxyethylmethacrylate (HEMA, 2.0\% in petrolatum, Chemotechnique Diagnostics), a dental filling material that the dentist had used in her daily practice. 


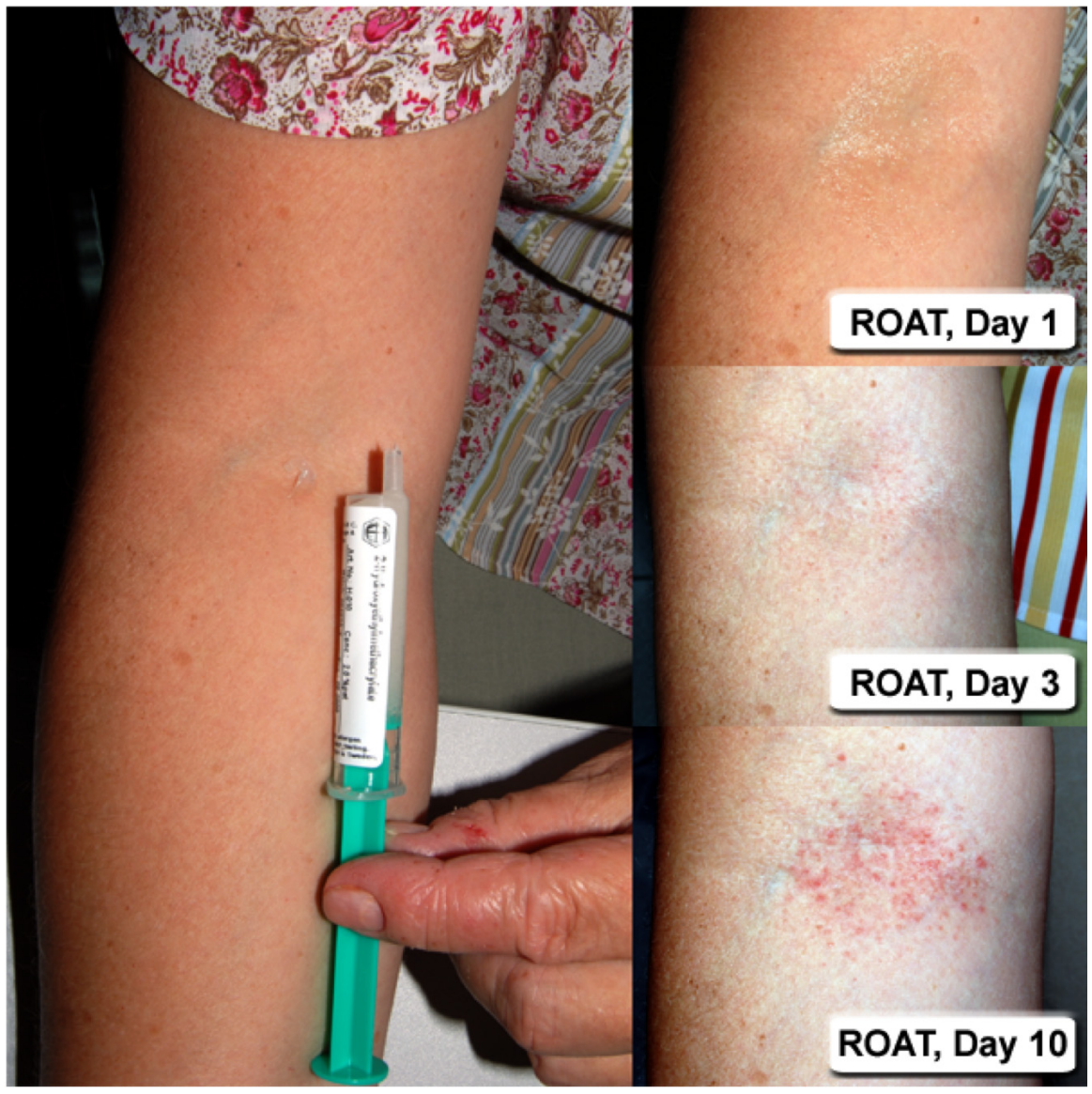

Fig. (4). In order to confirm the clinical relevance of the atypical patch test result with 2-Hydroxyethylmethacrylate (HEMA) in the patient presented in Fig. (3), the Repeated Open Application Test (ROAT) was undertaken. Faint papules appeared after 3 days of repeated application. After a further week of repeated application, there were clear signs of dermatitis, confirming that the hand dermatitis of the dentist was indeed caused by contact with HEMA. Avoidance of the substance led to an improvement in skin condition.

patch tests. Differences are in the test substances used (high molecular weight protein allergens - "atopens" instead of haptens), and the morphology of the positive patch test reaction (e.g. contact urticarial lesions, or papules at the orifices of sweat glands, which are the possible entrance for big protein allergens into the epidermis). In the last decades, publications appeared that pointed on the benefits of performing APT in atopic eczema, especially in the diagnosis of airborne dermatitis (caused e.g. by plant pollen or mites) and eczema related to food allergy [93]. In case of reading after 48 hours, the sensitivity and specificity of APT is estimated at $71-97 \%$ depending on the allergen tested [94]. However, results of large studies were also published that question the usefulness of APT in the diagnosis of atopic eczema [95]. A recent study shows satisfactory reproducibility of APT with aeroallergens in contrast to a very poor reproducibility of APT with food allergens [96]. Altogether, in contrast to "classical" patch tests, APT is not a routine diagnostic method at present, especially as regards food allergy - the official position paper of the European Academy of Allergology and Clinical Immunology (EAACI) stresses the need for further studies of the applicability of APT as a diagnostic tool [94].

\section{PERSPECTIVES FOR LABORATORY DIAGNOSIS}

Patch tests remain the method of choice and the "gold standard" in the diagnosis of contact allergy. However, due to the previously described limitations, contraindications, and rare yet possible complications, in some patients patch test is impossible to perform, or the results are difficult to interpret. Taking this into account, a reliable in vitro test for CA would be very welcomed. Despite some promising developments $[97,98]$, it seems that there is still a long way to go before a routine laboratory test for CA will be available (as reviewed in [22]).

\section{CONCLUSIONS}

1. The terms "contact allergy" and "allergic contact dermatitis" are not synonyms. The first term describes altered reactivity of the immune system with readiness to initiate inflammatory response to a hapten, whereas the second term refers to clinical symptoms of such inflammatory reaction in the skin.

2. In the general population, the prevalence of contact allergy ranges from $26-40 \%$ in adults and $13-37 \%$ in children, whereas the lifetime prevalence of allergic contact dermatitis is estimated at approximately $10 \%$.

3. Patch test is the method of choice and the "gold standard" in the detection of contact allergy and allergic contact dermatitis. Their execution increases the probability of correct diagnosis, shortens the time lapse between first visit and final diagnosis, increases the chance for full remission, and reduces therapy 
costs. Altogether, patch tests help in improving patients' quality of life.

4. The application of patch tests in not difficult, however, correct interpretation of the results requires appropriate training and experience.

\section{ACKNOWLEDGEMENTS}

For inspiring discussions and challenging questions, I cordially thank my collaborators and PhD students: Justyna Pietowska and Katarzyna Curzytek of the Institute of Dermatology, Krakow, and Magdalena Wladysiuk of the Company HTA Consulting, Krakow, as well as all participants of the Practical Patch Test Courses and Photopatch Test Courses organized at the Institute of Dermatology.

\section{REFERENCES}

[1] Vandenberg JJ, Epstein WL. Experimental nickel contact sensitization in man. J Invest Dermatol 1963; 41: 413-418.

[2] Basketter DA, Jefferies D, Safford BJ, et al. The impact of exposure variables on the induction of skin sensitization. Contact Dermatitis 2006; 55: 178-185

[3] Schlede E, Aberer W, Fuchs T, et al. Chemical substances and contact allergy - 244 substances ranked according to allergenic potency. Toxicology 2003; 193: 219-259.

[4] Sosted H, Basketter DA, Estrada E, Johansen JD, Patlewicz GY. Ranking of hair dye substances according to predicted sensitization potency: quantitative structure-activity relationships. Contact Dermatitis 2004; 51: 241-254.

[5] Akhavan A, Alghaithi K, Rabach M, et al. Allergic contact stomatitis. Dermatitis 2006; 17: 88-90.

[6] Caraffini S, Assalve D, Stingeni L, Lisi P. Allergic contact conjunctivitis and blepharitis from tobramycin. Contact Dermatitis 1995; 32: 186-187.

[7] Quan M. Vaginitis: meeting the clinical challenge. Clin Cornerstone 2000; 3: 36-47.

[8] Jensen CS, Menne T, Johansen JD. Systemic contact dermatitis after oral exposure to nickel: a review with a modified meta-analysis. Contact Dermatitis 2006; 54: 79-86.

[9] Spiewak R, Brewczynski PZ. Powiklania po stabilizacji plyta metalowa zlamania kosci udowej u chorej z alergia kontaktowa na chrom, nikiel i kobalt. Pol Tyg Lek 1993; 48: 651-652.

[10] Rahilly G, Price N. Nickel allergy and orthodontics. J Orthod 2003; 30: 171-174.

[11] Abdallah HI, Balsara RK, O'Riordan AC. Pacemaker contact sensitivity: clinical recognition and management. Ann Thorac Surg 1994; 57: 1017-1018.

[12] Koster R, Vieluf D, Kiehn M, et al. Nickel and molybdenum contact allergies in patients with coronary in-stent restenosis. Lancet 2000; 356:1895-1897.

[13] Guerra L, Rogkakou A, Massacane P, et al. Role of contact sensitization in chronic urticaria. J Am Acad Dermatol 2007; 56: 88-90.

[14] Malo JL, Cartier A, Gagnon G, et al. Isolated late asthmatic reaction due to nickel sulphate without antibodies to nickel. Clin Allergy 1985; 15: 95-99.

[15] Niordson AM. Nickel sensitivity as a cause of rhinitis. Contact Dermatitis 1981; 7: 273-274

[16] Schäfer T, Böhler E, Ruhdorfer S, et al. Epidemiology of contact allergy in adults. Allergy 2001; 56: 1192-1196.

[17] Dotterud LK, Smith-Sivertsen T. Allergic contact sensitization in the general adult population: a population-based study from Northern Norway. Contact Dermatitis 2007; 56: 10-15.

[18] Spiewak R. Allergische Kontaktdermatitis im Kindesalter. Eine Übersicht und Meta-Analyse. Allergologie 2002; 25: 374-381.

[19] Uter W, Hegewald J, Aberer W, et al. The European standard series in 9 European countries, 2002/2003 - first results of the European Surveillance System on Contact Allergies. Contact Dermatitis 2005; 53: 136-145.

[20] Spiewak R. Atopy and contact hypersensitivity: a reassessment of the relationship using objective measures. Ann Allergy Asthma Immunol 2005; 95: 61-65.

[21] Slaweta G, Kiec-Swierczynska M. Alergia kontaktowa u mlodziezy konczacej szkole podstawowa. Przegl Dermatol 1999; 86: 143-147.
[22] Spiewak R, Pietowska J, Curzytek K. Nickel - a unique allergen. From molecular structure to European legislation. Expert Rev Clin Immunol 2007; 3: 851-859.

[23] Modjtahedi BS, Modjtahedi SP, Maibach HI. The sex of the individual as a factor in allergic contact dermatitis. Contact Dermatitis 2004; 50: 53-59.

[24] Jensen CS, Lisby S, Baadsgaard O, et al. Decrease in nickel sensitization in a Danish schoolgirl population with ears pierced after implementation of a nickel-exposure regulation. Br J Dermatol 2002; 146: 636-642.

[25] European Parliament and Council Directive 94/27/EC of 30 June 1994 amending for the 12th time Directive 76/769/EEC on the approximation of the laws, regulations and administrative provisions of the Member States relating to restrictions on the marketing and use of certain dangerous substances and preparations. Official Journal L 1994; 188: 1-2.

[26] Aberer W. Vaccination despite thimerosal sensitivity. Contact Dermatitis 1991; 24: 6-10.

[27] Aberer W, Kränke B. Thimerosal is a frequent sensitizer but is not in the standard series. Contact Dermatitis 1995; 32:367-368.

[28] Belsito DV. The diagnostic evaluation, treatment, and prevention of allergic contact dermatitis in the new millennium. J Allergy Clin Immunol 2000; 105: 409-420.

[29] Bourke J, Coulson I, English J. Guidelines for care of contact dermatitis. Br J Dermatol 2001; 145: 877-885.

[30] Mowad CM. Patch testing: pitfalls and performance. Curr Opin Allergy Clin Immunol 2006; 6: 340-344.

[31] Lachapelle JM, Maibach HI. Patch testing and prick testing. A practical guide. Springer: Berlin, 2003.

[32] Rajagopalan R, Anderson RT, Sarma S, et al. An economic evaluation of patch testing in the diagnosis and management of allergic contact dermatitis. Am J Contact Dermat 1998; 9: 149-154.

[33] Academy of Allergy, Asthma and Immunology; American College of Allergy, Asthma and Immunology. Contact dermatitis: a practice parameter. Ann Allergy Asthma Immunol 2006; 97(3 Suppl 2): S1-S38.

[34] Spiewak R. Patch tests with popular topical antifungal drugs in eczema patients. Int Rev Allergol Clin Immunol 2000; 6: 136-138.

[35] Pietowska J, Curzytek K, Spiewak R. Frequencies of contact hypersensitivity to common haptens and psoriasis drugs among psoriasis patients. Allergy 2007; 62: S326.

[36] Spiewak R. Köbnerizing occupational contact allergy to thiuram in a farmer with psoriasis. Contact Dermatitis 2004; 51: 214-215.

[37] Spiewak R, Dutkiewicz J. A farmer's occupational airborne contact dermatitis masqueraded by coexisting rosacea: delayed diagnosis and legal acknowledgement. Ann Agric Environ Med 2004; 11: 329-333.

[38] Trautmann A. Allergiediagnose/Allergietherapie. Georg Thieme: Stuttgart, 2006.

[39] Spiewak R. Problems with interpreting the results of allergological patch tests: An analysis of test results in 196 patients with suspected contact dermatitis. Int Rev Allergol Clin Immunol 1997; 3: S36.

[40] Jonker MJ, Bruynzeel DP. The outcome of an additional patch-test reading on days 6 or 7 . Contact Dermatitis 2000; 42: 330-335.

[41] Veien NK, Hattel T, Justesen O, Norholm A. Aluminium allergy. Contact Dermatitis 1986; 15: 295-297.

[42] Tosti A, Vincenzi C, Peluso AM. Accidental diagnosis of aluminium sensitivity with Finn Chambers. Contact Dermatitis 1990; 23: 48-49.

[43] Lachapelle JM, Antoine JL. Problems raised by the simultaneous reproducibility of positive allergic patch test reactions in man. J Am Acad Dermatol 1989; 21: 850-854.

[44] Lazarov A, David M, Abraham D, Trattner A. Comparison of reactivity to allergens using the TRUE Test and IQ chamber system. Contact Dermatitis 2007; 56: 140-145.

[45] TRUE Test Study Group. Comparative multicenter studies with TRUE Test and Finn Chambers in eight Swedish hospitals. J Am Acad Dermatol 1989; 21: 846-849.

[46] Menne T, Dooms-Goossens A, Wahlberg JE, et al. How large a proportion of contact sensitivities are diagnosed with the European standard series? Contact Dermatitis 1992; 26: 201-202.

[47] Sherertz EF, Swartz SM. Is the screening patch test tray still worth using? J Am Acad Dermatol 1993; 29: 1057-1058.

[48] Bruze M, Andersen KE, Goossens A. On behalf of the European Society of Contact Dermatitis (ESCD) and European Environmental Contact Dermatitis Research Group (EECDRG). Recommendation to include fragrance mix 2 and hydroxyisohexyl 3-cyclohexene carboxaldehyde (Lyral) in the European baseline patch test series. Contact Dermatitis 2008; 58: 129-133. 
[49] Bruynzeel DP, Andersen KE, Camarasa JG, Lachapelle JM, Menne T, White IR. The European standard series. European Environmental and Contact Dermatitis Research Group (EECDRG). Contact Dermatitis 1995; 33: 145-148.

[50] Andersen KE, Burrows D, Cronin E, Dooms-Goossens A, Rycroft RJ, White IR. Recommended changes to standard series. Contact Dermatitis 1988; 19: 389-390.

[51] Mowad CM. Patch testing: pitfalls and performance. Curr Opin Allergy Clin Immunol 2006; 6: 340-344.

[52] van der Valk PG, Devos SA, Coenraads PJ. Evidence-based diagnosis in patch testing. Contact Dermatitis 2003; 48: 121-125.

[53] Bruynzeel DP, Ferguson J, Andersen K, et al. Photopatch testing: a consensus methodology for Europe. J Eur Acad Dermatol Venereol 2004; 18: 679-682.

[54] Bourke J, Coulson I, English J. Guidelines for care of contact dermatitis. Br J Dermatol 2001; 145: 877-885.

[55] Diepgen TL, Coenraads PJ. Sensitivity, specificity and positive predictive value of patch testing: the more you test, the more you get? ESCD Working Party on Epidemiology. Contact Dermatitis 2000; 42: 315-317.

[56] Marcussen PV. Specificity of epicutaneous tests in children. Acta Derm Venereol 1963; 43: 219-225.

[57] Hjorth N. Contact dermatitis in children. Acta Derm Venereol Suppl 1981; 95: 36-39.

[58] Veien NK, Hattel T, Justesen O, Norholm A. Contact dermatitis in children. Contact Dermatitis 1982; 8: 373-375.

[59] Pevny I, Brennenstuhl M, Razinskas G. Patch testing in children. (I) Collective test results; skin testability in children. Contact Dermatitis 1984; 11: 201-206.

[60] Roul S, Ducombs G, Taieb A. Usefulness of the European standard series for patch testing in children. A 3-year single-centre study of 337 patients. Contact Dermatitis 1999; 40: 232-235.

[61] Jacob SE, Burk CJ, Connelly EA. Patch testing: another steroidsparing agent to consider in children. Pediatr Dermatol 2008; 25: 8187.

[62] Nethercott JR, Holness DL. Validity of patch test screening trays in the evaluation of patients with allergic contact dermatitis. J Am Acad Dermatol 1989; 21: 568 .

[63] Brasch J, Henseler T, Aberer W, et al. Reproducibility of patch tests. A multicenter study of synchronous left-versus right-sided patch tests by the German Contact Dermatitis Research Group. J Am Acad Dermatol 1994; 31: 584-591.

[64] Mimesh S, Pratt M. Allergic contact dermatitis from corticosteroids: reproducibility of patch testing and correlation with intradermal testing. Dermatitis 2006; 17: 137-142.

[65] Bruze M, Isaksson M, Edman B, et al. A study on expert reading of patch test reactions: inter-individual accordance. Contact Dermatitis 1995; 32: 331-337.

[66] van Strien GA, Korstanje MJ. Site variations in patch test responses on the back. Contact Dermatitis 1994; 31: 95-96.

[67] Hindsen M, Bruze M, Christensen OB. Individual variation in nickel patch test reactivity. Am J Contact Dermat 1999; 10: 62-67.

[68] Aberer W. Die "falsch-positive" Epikutantest-Reaktion. Derm Beruf Umwelt 1988; 36: 13-16.

[69] Damian DL, Barnetson RS, Halliday GM. Effects of low-dose ultraviolet radiation on in vivo human cutaneous recall responses. Australas J Dermatol 2001; 42: 161-167.

[70] Lesiak A, Norval M, Sysa-Jedrzejowska A, et al. Elicitation of contact hypersensitivity after repeated suberythemal exposures of humans to solar simulated radiation: number of epidermal Langerhans cells. Contact Dermatitis 2007; 57: 224-229.

[71] Green C. The effect of topically applied corticosteroid on irritant and allergic patch test reactions. Contact Dermatitis 1996; 35: 331-333.

[72] Anveden I, Lindberg M, Andersen KE, et al. Oral prednisone suppresses allergic but not irritant patch test reactions in individuals hypersensitive to nickel. Contact Dermatitis 2004; 50: 298-303.

[73] Bonamonte D, Foti C, Antelmi AR, et al. Nickel contact allergy and menstrual cycle. Contact Dermatitis 2005; 52: 309-313.
[74] Mitchell JC. The angry back syndrome: eczema creates eczema. Contact Dermatitis 1975; 1: 193-194.

[75] Bruynzeel DP, van Ketel WG, von Blomberg M, et al. Angry back or the excited skin syndrome. A prospective study. J Am Acad Dermatol 1983; 8: 392-397.

[76] Isaksson M, Bruze M. Late patch-test reactions to budesonide need not be a sign of sensitization induced by the test procedure. Am $\mathrm{J}$ Contact Dermat 2003; 14: 154-156.

[77] Jensen CD, Paulsen E, Andersen KE. Retrospective evaluation of the consequence of alleged patch test sensitization. Contact Dermatitis 2006; 55: 30-35.

[78] Meneghini C, Angelini G. Intradermal test in contact allergy to metals. Acta Derm Venereol 1979; 59: 123-124.

[79] Moller H. Intradermal testing in doubtful cases of contact allergy to metals. Contact Dermatitis 1989; 20: 120-123.

[80] Christensen OB, Wall LM. Open, closed and intradermal testing in nickel allergy. Contact Dermatitis 1987; 16: 21-26.

[81] Herbst RA, Lauerma AI, Maibach HI. Intradermal testing in the diagnosis of allergic contact dermatitis. A reappraisal. Contact Dermatitis 1993; 29: 1-5.

[82] Trancik RJ, Maibach HI. Propylene glycol: irritation or sensitization? Contact Dermatitis 1982; 8: 185-189.

[83] Chang YC, Clarke GF, Maibach HI. The provocative use test (PUT) [repeated open application test (ROAT)] in topical corticosteroid allergic contact dermatitis. Contact Dermatitis 1997; 37: 309-311.

[84] Lasthein AB, Brandrup F. Contact dermatitis from chlorhexidine. Contact Dermatitis 1985; 13: 307-309.

[85] Hannuksela M, Salo H. The repeated open application test (ROAT). Contact Dermatitis 1986; 14: 221-227.

[86] Ekelund AG, Moller H. Oral provocation in eczematous contact allergy to neomycin and hydroxy-quinolines. Acta Derm Venereol 1969; 49: 422-426.

[87] Veien NK, Hattel T, Justesen O, Norholm A. Oral challenge with metal salts. (I). Vesicular patch-test-negative hand eczema. Contact Dermatitis 1983; 9: 402-406.

[88] Veien NK, Hattel T, Justesen O, Norholm A. Oral challenge with metal salts. (II). Various types of eczema. Contact Dermatitis 1983; 9: 407-410.

[89] Veien NK, Hattel T, Justesen O, Norholm N. Oral challenge with balsam of Peru. Contact Dermatitis 1985; 12: 104-107.

[90] Moller H, Ohlsson K, Linder C, et al. The flare-up reactions after systemic provocation in contact allergy to nickel and gold. Contact Dermatitis 1999; 40: 200-204.

[91] Dorado Bris JM, Aragues MM, Sols CM, Garcia DA. Contact sensitivity to pyrazinobutazone (Carudol) with positive oral provocation test. Contact Dermatitis 1992; 26: 355-356.

[92] Brasch J, Schnuch A, Uter W. Patch-test reaction patterns in patients with a predisposition to atopic dermatitis. Contact Dermatitis 2003; 49: 197-201.

[93] Wüthrich B. Contact allergy and "atopy patch tests" in atopic dermatitis. Acta Dermatovenerol Alp Panonica Adriat 1993; 2: 80-85.

[94] Turjanmaa K, Darsow U, Niggemann B, et al. EAACI/GA2LEN position paper: present status of the atopy patch test. Allergy 2006; 61: 1377-1384.

[95] Osterballe M, Andersen KE, Bindslev-Jensen C. The diagnostic accuracy of the atopy patch test in diagnosing hypersensitivity to cow's milk and hen's egg in unselected children with and without atopic dermatitis. J Am Acad Dermatol 2004; 51: 556-562.

[96] Ronchetti R, Jesenak M, Barberi S, et al. Reproducibility of atopy patch tests with food and inhalant allergens. J Biol Regul Homeost Agents 2008; 22: 27-33.

[97] Spiewak R, Czarnobilska E, Jenner B, Curzytek K, Pietowska J, Obtulowicz K. Contact allergy to nickel: Perspectives for laboratory diagnosis. Allergy 2007; 62: S435.

[98] Spiewak R, Moed H, von Blomberg BME, et al. Allergic contact dermatitis to nickel: modified in vitro test protocols for better detection of allergen-specific response. Contact Dermatitis 2007; 56: 63-9. 